\title{
Managing the Taiwan kindergarten evaluation system
}

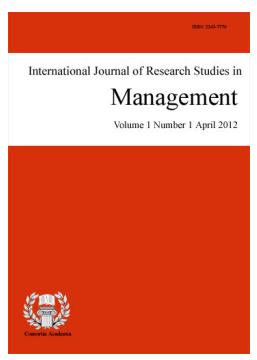

ISSN: 2243-7770

Online ISSN: 2243-7789

OPEN ACCESS

\section{Abstract}

The purpose of this study is to explore the content of Taiwan's kindergarten accreditation system and its current status, and set forth conclusions and recommendations for future references by policy-making authorities in kindergarten education. Using the documentary analysis method, results show that current evaluation system should practice more transparency in its administration. Furthermore, managers of such system should be encouraged to consider other countries' kindergarten accreditation systems for references.

Keywords: accreditation; kindergarten; education policy; evaluation; quality education 


\section{Managing the Taiwan kindergarten evaluation system}

\section{Introduction}

Driven by the city and county education authorities, Taiwan kindergarten accreditation has been presented with unique local characteristics. This study is to explore the development history of the kindergarten accreditation system, for a better understanding of the system's evolution and its current status, and from the policy aspect to explore the content of the system and its related issues. The main objective of the study is to explore the content of Taiwan's kindergarten accreditation system and its current status, and set forth conclusions and recommendations for references by policy-making authorities of kindergarten education.

\subsection{Terminologies}

Kindergarten accreditation: this is part of the overall school accreditation mechanism for assessing the achievement and merit of the implementation of kindergarten education, and it takes an accreditation model of professional, case-object oriented and institutional-based approaches, with a procedure falling into two categories of self-assessment and evaluator visiting survey. That is, kindergartens make self-assessments first, outside evaluators then pay visits to kindergartens to conduct site surveys, with the kindergarten self-assessments taken into considerations as references. Detailed overviews of the evaluation results are then consolidated for final reports and recommendations.

\section{Taiwan kindergarten accreditation}

\subsection{Taiwan kindergarten's evolution and development}

Established in 1897 in Tainan City, Guandi-Temple Kindergarten was the first Taiwanese-started kindergarten. The outset of "Kindergarten Curriculum Standards" was purposed to enhance children's physical and mental health, foster their good habits, inspire their basic knowledge and ability, and fulfill their proper joyfulness and happiness, as the educational goals of living knowledge and ability training. Not until 1956 was such institutions officially named as Kindergarten by Ministry of Education. And the kindergarten education law was enacted in 1981 which officially established the scope and legal status of the kindergarten. Initially, kindergartens were mostly public-based but were gradually replaced by private institutions. Private kindergartens have now become the mainstream in Taiwan (Hong, 2000).

\subsection{The number of public and private kindergartens and the number of children attending}

As of 2008, there were a total of 3,195 public and private kindergartens in Taiwan. Since 2001, however, the number of children attending kindergartens has been on the decline; meanwhile the number of public kindergartens has been increasing year by year, and the number of private kindergartens had a more significant increase in 2003 , only followed by a decreasing trend subsequently.

\subsection{Taiwan's kindergartens at a glance}

To start, Taiwan kindergartens are founded and must pass through the application process and complies with the following rules and regulations (Lin, 2007):

$>$ Enrolls students from age four and above;

$>$ Students are divided into whole (entire) day and half day sessions; 
In 2008, there are around 3,195 kindergarten schools all over Taiwan, with most of them are privately established kindergartens. Since 2001, the student population of the kindergartens continuously dropped; four to six year-old children total number is around 170,765. This number continually drops until now. Moreover, the private kindergartens take in twice the number of students of the public ones. Such phenomenon drastically shrinks the student populations and makes competition amongst schools even tougher. This also goes to show that current management of kindergartens in Taiwan is not easy. The issues of quantity and sacrificing the quality are important aspects that should not be taken easily (Jiang, 2002).

\section{Table 1}

Taiwan from 1998 to 2008 kindergartens survey table

\begin{tabular}{ccccccc}
\hline \multirow{2}{*}{ Year } & School & \multicolumn{2}{c}{ Public } & \multicolumn{2}{c}{ Private } & Total \\
& quantity & Number & Population & Number & Population & population \\
\hline 1998 & 2,874 & 1,065 & 63,633 & 1,809 & 147,162 & 210,795 \\
1999 & 3,005 & 1,160 & 67,457 & 1,845 & 139,166 & 206,623 \\
2000 & 3,150 & 1,230 & 72,491 & 1,920 & 146,810 & 219,301 \\
2001 & 3,234 & 1,288 & 74,091 & 1,946 & $\mathbf{1 4 7 , 6 4 2}$ & $\mathbf{2 2 1 , 7 3 3}$ \\
2002 & 3,275 & 1,331 & $\mathbf{7 5 , 6 0 8}$ & 1,944 & 144,029 & 219,637 \\
2003 & 3,306 & 1,358 & 73,267 & $\mathbf{1 , 9 4 8}$ & 142,301 & 215,568 \\
2004 & 3,252 & 1,348 & 71,832 & 1,904 & 139,592 & 211,424 \\
2005 & $\mathbf{3 , 3 5 1}$ & 1,474 & 67,565 & 1,877 & 138,050 & 205,615 \\
2006 & 3,329 & 1,507 & 71,314 & 1,822 & 113,480 & 184,794 \\
2007 & 3,283 & 1,528 & 71,622 & 1,755 & 104,230 & 175,852 \\
2008 & 3,195 & $\mathbf{1 , 5 4 4}$ & 71,656 & 1,651 & 99,109 & 170,765 \\
\hline
\end{tabular}

Source. Taiwan Ministry of Education (www.moe.gov.tw)

\subsection{The content of kindergarten accreditation (Worthen, Sanders, \& Fitzpatrick, 1997)}

Evaluation mainly seeks to answers the following four questions:

1. The definition of the goal and the limits of evaluation;

2. How to plan in order to achieves the predetermined goal (the need to design the strategy and the activity) of the kindergarten evaluation;

3. How to know whether to achieve the original goal of kindergarten evaluation;

4. How to gauge the kindergarten's progress?

\subsection{The meaning of the accreditation}

Wang and Sun (2001) argued that the significance of the accreditation was to maintain, to ensure, to enhance and to improve the kindergarten quality, by way of systematic collection of kindergarten operational data, which were analyzed to determine the performance of the administrative operations and used as the basis for improvement. The ultimate purpose of the kindergarten accreditation is to help kindergartens understand the status quo, and thus have them seek improvement strategies to self-inspire for better service quality and use the evaluation as the basis for administrative resolution to acquire quality education. The kindergarten accreditation is not merely to evaluate the quality of kindergarten education, but most importantly also to make an everlasting pursuance of high-quality education fulfillment into a certain level (Wang \& Sun, 2001).

$>\quad$ The government controlling organization, evaluation may take twists the superior prize and the counseling improvement basis, revises as the later kindergarten policy consideration; 
$>$ Evaluation may take the form of the self-appraisal, self-improvement, and progress check;

For the parents, evaluation may serve as to check the quality and on how to choose kindergarten;

$>$ For the students evaluation may take to the promotion of the kindergarten perfect development, guarantees the happiness of children.

\subsection{Indicators of accreditation}

The kindergarten evaluation standard may direct the execution and self-criticism of kindergarten educates or the plan. Therefore, evaluation standard should have the theory basis; clear evaluation standard will causes the localization of kindergarten evaluation work more clearly. To take the Taipei City kindergarten accreditation indicators as an example, the indicators of preschool administration include education philosophy, kindergarten guidance, kindergarten development, administrative operations, personnel system, financial system, general administration system and school bus system; the indicators of teaching and nursing include curriculum and teaching, interaction between the kindergarten and community, health care and nutritional meals, and growth of the principal and teachers; the indicators of teaching facility and public safety include the kindergarten area size and construction, teaching scenarios and planning ideologies, teaching facilities and their usage management, and public safety and environmental sanitation (Lin, 2007).

\subsection{The accreditation process}

Evaluation flow will be the evaluator chooses evaluation standard systematization, Collection the pertinent data of the quantity object, Comparison the evaluation standard, makes the careful evaluation, the supervision comments the quantity object to Improves its service quality (Chin, 1998).

> Pre staged planning phase: establish a team of accreditation planning to determine the accreditation issues, purpose, scope and content, and then create evaluation questions and referencing indicators, followed by choosing accreditation staff, setting up accreditation procedure as well as selecting methods of data collection, analysis and interpretation.

Implementation phase: develop quality data collection tools, analyze data, make conclusions, offer policy recommendations, and write accreditation summary reports.

> Application phase: publish accreditation results, promulgate accreditation reports and retrieve feedbacks, and make use of the outcomes for applications.

\subsection{The evaluation plan}

The plan should have the following issues on mind: What to evaluate? Include the narration of the kindergarten evaluation goal, expectation and result, Benefit degree of parents and children, how many evaluation conclusions. Who will use the accreditation results? How to use? What are desired to know about? To those who are interesting the kindergarten evaluation conclusion, what are the topics they concern, what information they want, and how to use? To what problems the evaluation is intended to find answers? What kind of information can be used to answer the questions? What is the kindergartens need? Who will benefit after the kindergarten evaluation? How to benefit? What resources are required? What kind of information depends on the evaluators want to know about the kindergartens (Jiang, 2002).

\subsection{The evaluation model}

The kindergarten evaluation mostly use the CIPP evaluation model developed by Stufflebeam (2000).

$>\quad$ The basic orientation of context evaluation will be to confirmation the advantage and disadvantage of 
kindergartens, and provides the improvement direction.

$>\quad$ The basic orientation of context evaluation will be to confirmation the advantage and disadvantage of kindergartens, and provides the improvement direction.

$>$ Process evaluation: Continuing check the Implementation of each content, record the process to document.

$>$ Product evaluation means survey, explanation as well as judgment the achievements of the kindergartens, gather data to description and judgment.

Currently kindergarten accreditation model has been slowly transformed into case-object oriented, in that the accreditation objectives, methods and standards are determined by all stakeholders concerned, including the school directors, teachers, parents, government officials, experts and scholars, in a way of listening to their voices and taking into account their views in order to minimize resistance in the implementation of the accreditation.

\subsection{The evaluation staff}

The staff helps the public understand the results of the kindergarten accreditation and how to make applications. They design accreditation plans to meet the purposes set by the consigners and implement the actual works which include individual or group interviews, design and implementation of surveys, observation or measurement of the extent of the need for change, review of document files, participation in relevant meetings, as well as interpretation of the results of the collected evaluation data.

The having condition of the kindergarten evaluation personnel include (Payne, 1994):

1. Has the quantity and quality knowledge of evaluation theory.

2. Can distinguish the process of research and evaluation.

3. Can plan, design, assessment and analysis evaluation plan.

4. Can distinguish what kind of information is suitable the evaluation plan and need, and use suitable process of data collecting and analysis.

5. Can management and Maintenance the evaluation data.

6. Can composition the brief evaluation report, make clear communication with kindergarten, to answer the questions.

7. With the experiences of evaluation standards construction.

8. Observes the evaluation ethics.

\subsection{Self assessment}

In the current implementation of kindergarten accreditation, self-assessment is usually the first step, which is an essential course in the odyssey of continuous self-development and self-reshaping of style and vision, and will continue to play as a kindergarten self-monitoring mechanism; The accreditation team is often formed within the organization of the kindergarten, and is intended to address the kindergarten's needs as improvement references; interactive observation and learning can be arranged and exercised inside the kindergarten or the kindergarten may invite other kindergartens to visit and make evaluations, by doing so to achieve a double effect of motivation and learning (Patton, 1990). 


\subsection{External assessment}

The external assessment flow includes the following: Listening to the kindergarten director's briefing to understand the kindergarten's position and characteristics, visiting the kindergarten's various teaching activities and facilities, observing the teachers' activities, reviewing document files, and making interviews with teachers, administrators, students and parent representatives; gathering relevant information, making access to archived information, holding a forum to discuss the outcomes of the accreditation before its close and making verbal comments and exchanging views with the accredited kindergarten. After the accreditation is done, reports are produced and submitted to the accreditation organizer.

\subsection{Data collection method}

The accreditation criteria and standards, whether in terms of quality or quantity, must be clear and objective in presenting the status of the accredited kindergarten, in order to genuinely spot kindergarten administrative problems and seek improvement strategies. The emphasis of kindergarten-based self- development has been getting weight in recent years. Accordingly, to have more comprehensive overview of the kindergarten's status, the quality of data collection has now become the focus of the interaction between the kindergarten and its evaluators.

\subsection{Applications of the accreditation results}

Evaluation report should announce are the mutual recognition of everybody, how to cleverly use the accreditation results and enable the kindergarten to set its performance in full play should be the major issue following the accreditation results. Evaluation report announcement are usually divides into two kinds, one kind is to publish the entire report publicly, to satisfied the knows right of the social populace, another kind is only afford the report to the evaluated kindergarten, to reduces restlessly of the evaluated kindergarten (Green, 1994).

\section{Methods}

To achieve the purpose of the research, this study uses documentary analysis method to consolidate the government announcements, laws and regulations, research reports and documentation records, and then probes into these data for analyses. This study will use the written documents and relevant files collected through the literature reviews for analyses. Kindergarten evaluation system includes evaluation goal, evaluation plan, evaluation standard, evaluation personnel, evaluation data collecting, evaluation preparation, self-evaluation, outside evaluation, evaluation report.

\section{Conclusion}

\subsection{Make public the accreditation plans and standards on websites}

The cities and counties of Taiwan publicize their evaluation plans on the websites of their local Education Departments before proceeding with the works, and the publication mainly aims at the kindergartens to be evaluated.

\subsection{Hold conferences in advance to explain the kindergarten accreditation, for a better communication and mutual understanding}

As a practice in Taiwan, briefings are given prior to conducting accreditation. A full day is taken to illustrate the evaluation criteria and help communications among parties involved.

\subsection{Conduct self-assessments prior to official evaluations}


Prior to the official evaluation, kindergartens in Taiwan must make self-assessments in advance, based on the criteria proposed by evaluators. As a result, kindergartens will do their best to present their own approaches and features in the self-assessment.

\subsection{The effect of counseling prior to evaluation}

Visits to the kindergartens prior to the official accreditation may vary depending on the local government budgets. To take Taipei County as an example, about half a year prior to the accreditation, a team of evaluators will visit the kindergarten for survey and counseling - they simulate the evaluation content and explain the kindergarten's merits and drawbacks; for subjects that need immediate improvement or can be improved without difficulties, the kindergarten will be explicitly advised to make improvement, and the valuators will consider the accreditation work done. However, reports of the forward counseling will be promulgated for references by external evaluators.

\subsection{The accreditation is benchmarked with quantitative analysis, while reports are mainly aimed at feature explanation}

The accreditations conducted in Taiwan's cities and counties are divided into major categories - three categories at the least, which are further subdivided into smaller categories; sometimes the major categories can be as many as twelve. Evaluation officers are pursuant to the spindle of each major category to contrast with the kindergarten's documents as well as hardware and software facilities, and item weights are taken into consideration in the statements of the accreditation reports. Taiwan accreditation reports use text statements to convey the results, with plain words easy to understand, and avoid excessive criticism on kindergartens, but still pinpoint necessary improvements, so that kindergartens can grasp the directions of their efforts.

\section{Recommendations}

\subsection{Early childhood education policies}

Set up dedicated accreditation agencies. Similar to the evaluation center, impetus by government or learned society to complete the evaluation work, make the normal operation kindergarten evaluation.

$>\quad$ Select and train the evaluators. Continues to carry on training evaluation personnel, establishment human resources storehouse, and evaluation personnel must have the experience of kindergarten evaluation, kindergarten teaching experience and pass the training course, to enhance the quality and uniformity confidence level of evaluation personnel.

$>$ Re-start accreditation works as soon as possible. The kindergarten stopping evaluation surpasses above five years. Should advance evaluation work right now, for parents, children and all kindergarten personnel confidence, may be the most important policy.

$>\quad$ Provide references for integrated policy making of child care. Kindergartens and daycare centers conformity will be implemented next year. Suggestion in the future will Increases the researches of kindergarten policy between different country, to make the kindergartens and daycare centers conformity be better.

\subsection{Practical aspects of the accreditation system}

$>\quad$ The time needed for visit and evaluation should take into account the kindergarten's scale and the accreditation standards.

The accreditation standards should be flexible. After the kindergarten evaluation, gather the opinions 
of the evaluation-related people, to revision the kindergarten evaluation standard suitably.

$>$ Ensure the fulfillment of the accreditation objectives. Evaluation goal must be reachable, Consideration reality and ideal stratification plane, kindergarten should self-evaluation regular, not only before the evaluation.

$>$ Enhance the depth of self-assessment. Should put the self-evaluation work to be the most evaluation preparation work.

> Reports and applications of the accreditation results should be made public. Kindergarten evaluation report should be announced in government homepage. Provides parents the reference of choosing kindergarten, and maintenance routine renewal homepage.

$>$ Track the follow-up activities and provide counseling. Kindergarten in five years after evaluated, should propose the year self-inspection, continues maintains with progresses to self-promotion.

\subsection{Future directions of the study}

> Take in other countries' kindergarten accreditation systems for references. More experts can invest the research topics, multiplex research to increases the research quantity, helps us to understand kindergarten evaluation thorough.

$>$ Use different methods for the study. Suggest focusing deep research the ten research variables in this research in the future, quality and quantity will be variable similarly.

\section{References:}

Chin, J. M. C. (1998). Educational administration: The practical part [In Chinese]. Taipei City: Wu-Nan Cultural Enterprise.

Green, D. (1994). What is quality in higher education. London: Society for Research into Higher Education.

Hong, F. C. (2000). Exploration of the historical development and future compulsory education policy of the Taiwan early childhood education [In Chinese]. Unpublished Doctoral dissertation. Institute of Education, National Taiwan Normal University.

Jiang, L. L. (2002). Taipei county evaluation program of kindergarten counseling [In Chinese] (Vol. 136): Birdsfamily.

Lin, H. F. (2007). Study of Taipei city meta-nursery evaluation. Taipei: Kang-Ning Junior College of Medical Care.

Patton, M. Q. (1990). Qualitative evaluation and research method. Newbury Park, CA: Sage.

Payne, D. A. (1994). Designing educational project and program evaluation - A practional everview based on research and experience. Boston: Kluwer Academic Publishers. $<$ http://dx.doi.org/10.1007/978-94-011-1376-2>

Stufflebeam, D. L. (2000). The CIPP model for evaluation. In D. L. Stufflebeam, G. F. Madaus \& T. Kellaghan (Eds.), Evaluation models: Viewpoint on educational and human services evaluation (2nd ed., pp. 279-317). Boston: Kluwer Academy Publishers.

Wang, P. L., \& Sun, L. W. (2001). Study of the selection system of kindergarten accreditation committee members of Taipei City: A research project of Taipei city government education department [In Chinese]. Taipei City: Department of Early Childhood Education, Taipei Municipal University of Education.

Worthen, B. R., Sanders, J. R., \& Fitzpatrick, J. L. (1997). Program evaluation: Alternative approaches and practical guidelines. New York: Longman. 